\title{
Newsletters that work, part 2: Confent and impact
}

Barbara Blake, director of the Rowlett (TX) Public Library, presented the final session of her two-part workshop, "Newsletters That Work," at the ALA Annual Conference in July. The first session dealt with newsletter production and layout and took place at ALA Midwinter in February 1996 (CERL News, May 1996). That session focused on substantive rather than technical issues, such as writing style, objectives, content, and audience impact.

Blake reviewed the unique characteristics of an organizational newsletter. It should be like a letter to the reader, personal in style and commentary, designed $\mathrm{o})$ communicate specific information rather than impress. It should be brief and be ahle to be scanned and absorbed quickly so that it provides immediate satisfaction rather than creating a burden. It should fill the void left by the decline of letter writing, presenting recipients with something fun and interesting in their daily mail.

\section{A few writing tips}

Blake offered the following newsletter tips:

- Simplicity. Use short simple declarative sentences without introductory phrases and complex clauses. Be succinct in stating what your library is trying to accomplish and how others can help; don't provide a lot of background information. Indent paragraphs, rather than using a block style; and use "you" to create an intimate feel.

- Brevity. The longer the article is, the less likely it is to be read. Aim for a series of telegraphs rather than essays. No article should be so long that it has to be continued on a following page. The reader should be able to absorb a whole article while waiting "on hold" on the telephone. Use lists. Avoid redundancy; make each word count.

- Clarity. Use the active voice and strong verbs. Avoid jargon, adjectives, and metaphors. Organize points logically, for example, chronologically or into "pros" and "cons." Double check for accuracy, correct spelling, and proper usage. Be direct, even when discussing library problems; don't attempt to hide problems or explain them away.
Blake advised beginning newsletter writers to pace themselves, taking breaks when needed; to set reasonable deadlines and start projects early; to reward themselves after completing each article; and to avoid perfectionism. Newsletter writing is a skill that requires regular practice. It is also a job that eventually leads to burnout; after you've been editing your library newsletter for a number of years, pass it on to someone else with a fresh perspective.

\section{Five basic steps}

Blake listed the five basic steps in newsletter writing: drafting, revising, typing or keying, editing, and proofreading.

She emphasized the importance and difficulty of meticulous proofreading, and advised having somebody else proofread your writing if possible, or setting an article aside and proofreading it yourself the next day. She advised paying special attention to titles, headlines, subheadings, and first lines, which are particularly likely to have undetected errors.

She distinguished among the three types of successive editing: concept. line, and copyediting. Each type should be undertaken separately, with a short waiting period between each step.

Blake finished the session by answering questions about newsletter writing. She advised ameliorating the problem of writing for multiple audiences by using several specialized columnists, bullets, and pull-out boxes. She suggested using the "let me interview you" technique to flatter tardy contributors and elicit needed information. She noted that newsletter editors need to be sensitive to internal organizational politics and may want to consider organizing issues and articles thematically rather than by department, and quoting rather than paraphrasing the ideas of difficult colleagues.

Blake's views on both content and production are described at length in her Creating Newsletters, Brochures, and Pamphlets: A Howto-Do-It Manual, coauthored with Barbara Stein (Neal-Schuman, 1992).-Margaret Gordon, University' of California, Santa Criz 


\section{Live History from Chronicle!}

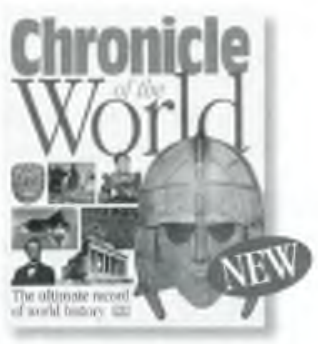

The history of humanity, from B.C. $3.500,000$ to today, is captured in one volume through concise journalistic entries and extensive illustrations.

Illustrations, photographs, reproductions. Appendix, index

ISBN: 0-7894-0334-X $-\$ 59.95$ Hardcover

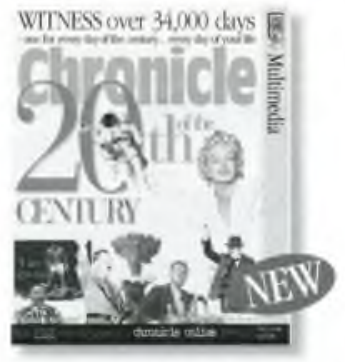

Here is the only CD-ROM that reveals the historic events for every single day of the 20th century up to 1996. Seven search engines provide unprecedented access to text, video, sound, and photographs.

Windows ISBN: 0-7894-1218-7

Macintosh ISBN: 0-7894-1222-5 ESP: $\$ 39.95$ CD-ROM

\section{Also Available:}

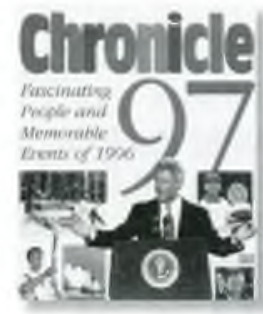

ISBN: 0-7894-1396-5

$\$ 12.95$ Paperback

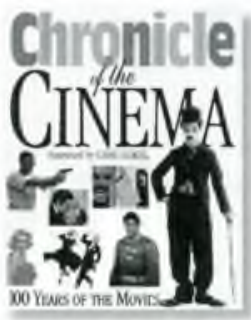

ISBN: 0-7894-0123-1

$\$ 59.95$ Hardcover

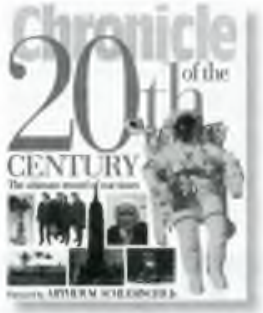

ISBN: 0-7894-0332-3

$\$ 69.95$ Hardcover

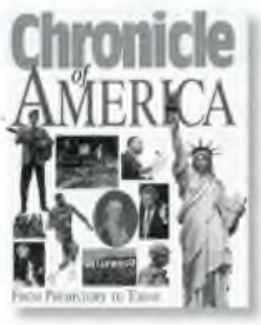

ISBN: 0-7894-0124-X

$\$ 59.95$ Hardcover

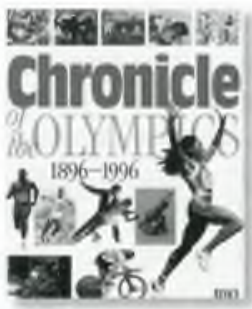

ISBN: 0-7894-0608-X $\$ 29.95$ Hardoover

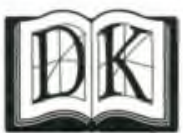

DK Publishing, Inc. 95 Madison Avenue New York, NY 10016 http://www.dk.com Available from your regular supplier, or call 1-888-DLAL-DKP 